\title{
Retinoids in the treatment of glioma: a new perspective
}

This article was published in the following Dove Press journal:

Cancer Management and Research

6 August 2012

Number of times this article has been viewed

\section{Anthony R Mawson \\ Department of Health Policy and Management, School of Health Sciences, College of Public Service, Jackson State University, Jackson, MS, USA}

\begin{abstract}
Primary brain tumors are among the top ten causes of cancer-related deaths in the US. Malignant gliomas account for approximately $70 \%$ of the 22,500 new cases of malignant primary brain tumors diagnosed in adults each year and are associated with high morbidity and mortality. Despite optimal treatment, the prognosis for patients with gliomas remains poor. The use of retinoids (vitamin A and its congeners) in the treatment of certain tumors was originally based on the assumption that these conditions were associated with an underlying deficiency of vitamin A and that supplementation with pharmacological doses would correct the deficiency. Yet the results of retinoid treatment have been only modestly beneficial and usually short-lived. Studies also indicate that vitamin A excess and supplementation have pro-oxidant effects and are associated with increased risks of mortality from cancer and other diseases. The therapeutic role of vitamin A in cancer thus remains uncertain and a new perspective on the facts is needed. The modest and temporary benefits of retinoid treatment could result from a process of feedback inhibition, whereby exogenous retinoid temporarily inhibits the endogenous synthesis of these compounds. In fact, repeated and/or excessive exposure of the tissues to endogenous retinoic acid may contribute to carcinogenesis. Gliomas, in particular, may result from an imbalance in retinoid receptor expression initiated by environmental factors that increase the endogenous production of retinoic acid in glia. At the receptor level, it is proposed that this imbalance is characterized by excessive expression of retinoic acid receptor- $\alpha$ (RAR $\alpha)$ and reduced expression of retinoic acid receptor- $\beta$ (RAR $\beta$ ). This suggests a potential new treatment strategy for gliomas, possibly even at a late stage of the disease, ie, to combine the use of a RAR $\alpha$ antagonist and a RAR $\beta$ agonist. According to this hypothesis, the RAR $\alpha$ antagonist would be expected to inhibit RAR $\alpha$-induced gliomas, while the RAR $\beta$ agonist would suppress tumor growth and possibly contribute to the regeneration of normal glia.
\end{abstract}

Keywords: glioma, retinoids, pathogenesis, epidemiology, hypervitaminosis A

\section{Classification and diagnosis of glioma}

Primary brain tumors are among the top ten causes of cancer-related deaths in the US. Malignant gliomas account for approximately $70 \%$ of the 22,500 new cases of malignant primary brain tumors diagnosed in adults in the US each year and are associated with high morbidity and mortality. Despite optimal treatment, the median survival is $12-15$ months for patients with glioblastoma and 2-5 years for those with anaplastic glioma. ${ }^{1}$

Brain tumors are classified according to the type of cell in which they occur, diagnosed on morphological criteria, and graded according to World Health Organization (WHO) criteria. This system of classification and diagnosis provides an estimated prognosis of the natural course of the disease. ${ }^{2}$ 
Gliomas develop in glial cells and are named after the types of glial cell with which they share histological features. The main forms of glioma are ependymomas, astrocytomas (of which glioblastoma multiforme is the most common), oligodendrogliomas, and mixed gliomas, such as oligoastrocytomas, which contain cells from different types of glia. Gliomas are further categorized according to their grade, as determined by pathologic evaluation of the tumor. They include low-grade gliomas (WHO grade II), which are nonanaplastic, ie, well differentiated, and high-grade gliomas (WHO grade III-IV), which are anaplastic, undifferentiated, and have a poor prognosis. Among adults, the most frequent types of brain tumor are glioblastomas and other astrocytic tumors, meningiomas, acoustic neuromas, and pituitary gland tumors. ${ }^{3}$ Gliomas are the most common forms of brain cancer, tend to be fast growing, diffusely invasive, poorly understood, and highly resistant to treatment. ${ }^{4}$

\section{Signs and symptoms of glioma}

The signs and symptoms of brain tumors result partly from increasing pressure within the skull as the tumor grows. Other symptoms are secondary to effects on nearby structures and inflammation associated with malignant invasion. The most common symptoms are headache, vomiting, generalized or focal seizures, impaired movement or sensation, loss of sense of smell, difficulty walking, vertigo, hearing loss, visual field defects or loss of vision, nystagmus, tremor, incontinence, deterioration in mental and behavioral status, memory loss, difficulty speaking or understanding speech, excessive thirst or appetite, inappropriate denial of illness, injury or bodily defects, and visual hallucinations. ${ }^{5}$

\section{Epidemiology}

There are approximately 19 different International Classification of Disease (ICD-9) codes for brain tumors. There is a tendency toward a higher incidence of glioma in highly developed, industrialized countries, with some reports indicating that people of European origin have higher incidence rates than African or Asian populations. ${ }^{6}$ In the US, both incidence and mortality rates are substantially higher among whites than among people of other racial or ethnic groups, and men have higher incidence and mortality rates than women in all racial groups. Incidence and mortality rates for cancers of the brain and central nervous system have decreased slightly in the past decade. Among children, the incidence of brain and central nervous system cancers has risen slightly over the past three decades, while the death rate has fallen slightly over the same period. It is estimated that $\$ 3.7$ billion is spent in the US each year on treatment of brain cancer. ${ }^{7}$

Figure 1 shows trends in mortality rates for brain cancer and other nervous system cancers from 1975 to 2008 . Mortality rates among both blacks and whites in the author's home state of Mississippi steadily increased from 1975 to the late 1990s, then declined in whites but continued to rise in blacks. In the US as a whole, death rates among both blacks and whites have declined since about $1990 .{ }^{8}$

With the exception of pilocytic astrocytomas (WHO grade I), the prognosis for patients with glioma is poor. Fewer than $3 \%$ of glioblastoma patients are still alive 5 years after diagnosis, older age being the most significant prognostic factor for a poorer outcome. ${ }^{6}$

\section{Risk factors}

Many environmental and lifestyle factors, including several occupations, environmental carcinogens, and diet, are reportedly associated with an increased risk of glioma, but the only factor unequivocally associated with an increased risk is both low-dose and high-dose therapeutic ionizing radiation. In particular, children treated with irradiation for acute lymphoblastic leukemia show a significantly elevated risk, often within 10 years of therapy. ${ }^{6}$ However, overall, little is known about the risk factors and causal mechanisms for glioma. Limited evidence suggests that gliomas are associated with traumatic brain injury, cigarette smoking, use of hair dyes, and exposure to certain chemicals and viruses. For instance, studies suggest associations between prior head injury and meningioma in men, ${ }^{9}$ between smoking unfiltered cigarettes and an increased risk of adult glioma, ${ }^{10,11}$ and a null or inverse association between glioma and alcohol consumption. ${ }^{12}$ An international case-control study showed an inverse association between allergic diseases and glioma, but not with meningioma. ${ }^{13}$ With regard to viral etiologies, during the 1950s and 1960s live polio vaccines were contaminated with simian monkey virus (SV40), and a case-control study of children with medulloblastoma showed that significantly more cases than controls had been exposed to SV40. ${ }^{14}$ A cohort study in Germany similarly indicated that exposure to SV40 in childhood was associated with a slightly higher risk of glioblastoma and medulloblastoma. ${ }^{15}$ However, a later study reported no difference in brain tumor risk between exposed and nonexposed groups. ${ }^{16}$

\section{Hypothesis}

While knowledge of the risk factors and pathogenesis remains sparse, it is postulated here that long-term exposure to the risk 


\section{Historical trends (1975-2008)}

Mortality, brain and ONS both sexes, all ages

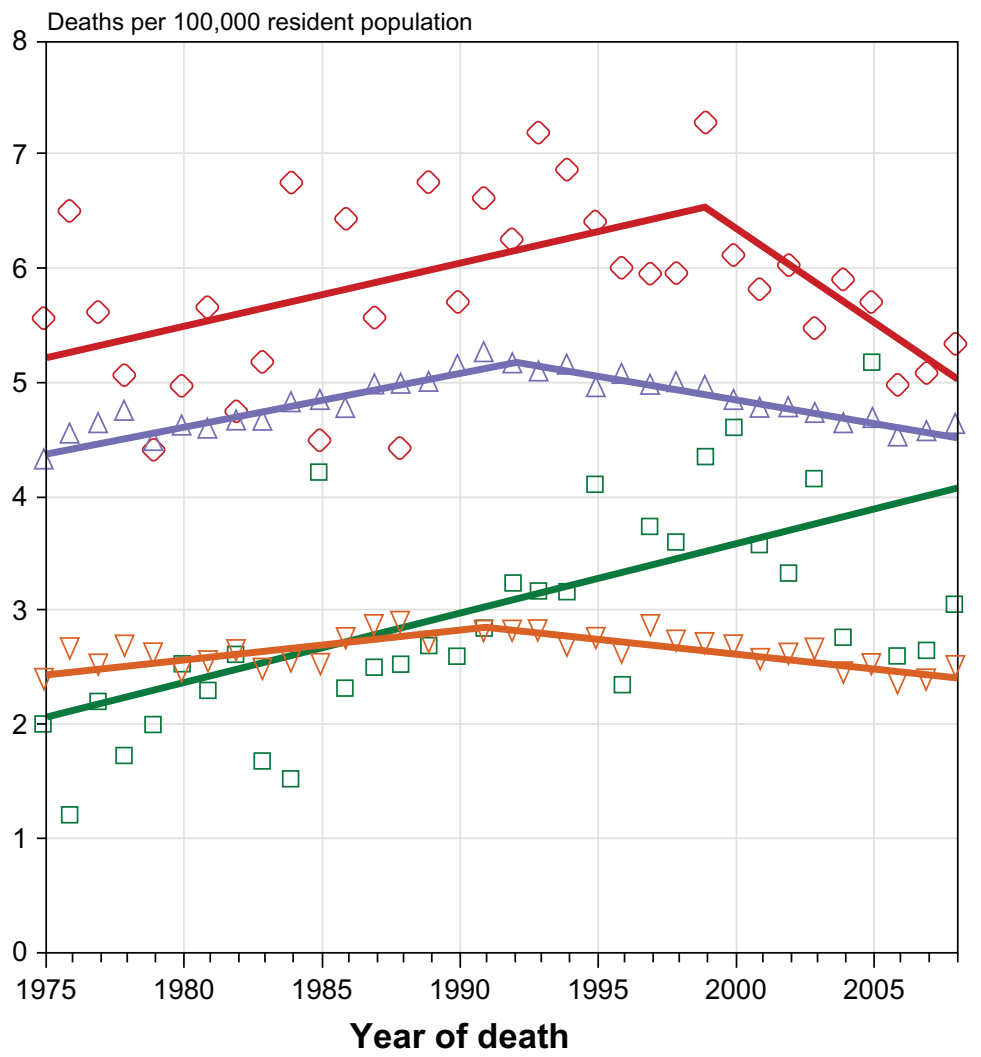

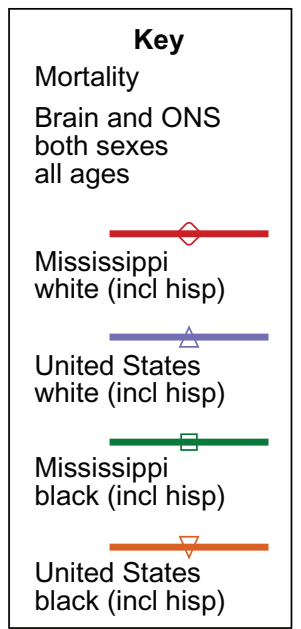

Figure I Trends from 1975-2008 in mortality rates for brain cancer and other nervous system cancers in the United States (Cancer.gov [homepage on the internet]. State Cancer Profiles. National Cancer Institute; 2012. Available from http://statecancerprofiles.cancer.gov/cgi-bin/quickprofiles/profile.pl?28\&076) Accessed July 20I2.

Notes: Death data provided by the National Vital Statistics System public use data file. Death rates calculated by the National Cancer Institute using SEER Surveillance, Epidemiology, and End Results (SEER) Program statistics.. Death rates (deaths per 100,000 population per year) are age-adjusted to the 2000 US standard population (19 age groups: $(<\mathrm{I}, \mathrm{I}-4,5-9, \ldots, 80-84,85+)$. Population counts for denominators are based on Census populations as modified by NCl. The US populations included with the data release have been adjusted for the population shifts due to hurricanes Katrina and Rita for 62 counties and parishes in Alabama, Mississippi, Louisiana, and Texas. The 1969-2008 US Population Data File is used with mortality data.

Created by statecancerprofiles.cancer.gov on 05/08/20I2 10:5I pm. Regression lines calculated using the Joinpoint Regression Program.

Abbreviations: $\mathrm{NCl}$, National Cancer Institute; ONS, other nervous system

factors noted above, either singly or in combination, initiates the growth of glioma via a common pathway that involves prolonged intermittent exposure of the glia to endogenously synthesized retinoic acid. It is suggested that the net effect of these processes is an increase in the accumulation of retinoic acid in glial cells, resulting in inflammatory changes involving an imbalance in retinoid receptor isoform expression characterized by retinoic acid receptor- $\alpha(\mathrm{RAR} \alpha)$ overexpression and retinoic acid receptor- $\beta$ (RAR $\beta)$ underexpression.

\section{Retinoids}

Retinoids (the collective term for vitamin A and its natural and synthetic congeners) are fat-soluble molecules that are essential in low concentration for numerous bodily functions, including embryogenesis, normal development, and tissue differentiation, but in higher concentration they can be cytotoxic, mutagenic, and teratogenic. ${ }^{17}$ Vitamin $\mathrm{A}$ is derived from dietary sources and is stored as retinyl esters in the liver (about 80\%), with lesser amounts in the lungs, kidneys, and bone marrow. Retinol is transported as retinol-binding protein from the liver to the target tissues, where it is enzymatically converted to retinaldehyde and subsequently to retinoic acid. The latter serves as a ligand for the retinoic acid receptors and the retinoid $\mathrm{X}$ receptors, each of which has three isoforms, ie, $\alpha, \beta$, and $\gamma$. These receptors form heterodimers and are responsible for the expression of numerous genes. ${ }^{18,19}$

Retinoid signaling pathways stimulate neurogenesis, dendritic growth of hippocampal neurons, and higher cognitive functions, such as spatial learning and memory formation. ${ }^{20,21}$ Components of the retinoid signaling system involved in retinoid metabolism and transport include retinal dehydrogenases and cellular retinoid binding proteins, and are found 
in the adult brain. Many neuronal genes are responsive to retinoids. ${ }^{18}$ High levels of RAR $\alpha$ mRNA are normally present in the hippocampus, cerebellum, and hypothalamus; conversely, RAR $\beta$ mRNA is prominently expressed in the developing central nervous system and in nonkeratinizing oral cavity epithelial cells, but is undetectable in oral cavity squamous cell carcinoma cell lines. ${ }^{22}$ Cultured astrocytes express the key enzyme mRNAs of retinoic acid biosynthesis and actively produce all-trans retinoic acid; moreover, blockage of retinoic acid signaling by the pan-RAR antagonist, AGN193109, prevents glia-induced neuron formation by noncommitted stem cells, which has been interpreted as suggesting that retinoic acid contributes to astroglia-induced neuronal differentiation. ${ }^{23}$ Astrocyte-derived retinoic acid is considered a key factor in neurogenesis. Recent evidence indicates that primary rat astrocytes but not neurons biosynthesize retinoic acid using multiple retinol dehydrogenases and retinaldehyde dehydrogenases. Astrocytes secrete retinoic acid into their medium whereas neurons sequester retinoic acid. ${ }^{21}$

\section{Uses of retinoids in cancer treatment}

Synthetic forms or analogs of retinoic acid (eg, 13-cisretinoic acid) have long been used to treat several diseases, including numerous forms of cancer. The use of retinoids in the treatment of cancer began with the observation that the flattened, keratinized epithelial cells in lung cancer tissue were similar to those seen in vitamin A deficiency. ${ }^{24}$ Retinoid signaling is often compromised early in carcinogenesis, which has suggested a causal role for reduced vitamin A in tumor development. ${ }^{25}$ Hence, supplementation with pharmacologic doses of retinoids was thought to provide an effective treatment by correcting an underlying deficiency. In one such study on the use of the analog 13-cis-retinoic acid for glioma, ${ }^{26}$ the results were described as "modestly beneficial". Several case-control studies also appeared to support the vitamin A deficiency hypothesis by showing that plasma retinol concentrations were low, but not necessarily deficient, in cancers of the lung, prostate, and breast. ${ }^{22}$ All-trans retinoic acid (ATRA) significantly inhibited proliferation of glioma cells, accompanied by upregulation of expression of Axin and altered subcellular distribution of catenin. ${ }^{27}$ Inflammatory cytokine release from astrocytes in vitro was also reduced by ATRA. ${ }^{28}$ This was a study designed to investigate the central nervous system regulation of inflammation mediated by microglia and astrocytes, in which murine astrocyte cultures were treated with bacterial lipopolysaccharides.
Cells responded to lipopolysaccharides with a strong upregulation of proinflammatory cytokines and chemokines. Treatment with ATRA suppressed mRNA expression and protein release of several important cytokines, ie, interleukin (IL)-1 $\beta$ (4\%), IL-6 (21\%), tumor necrosis factor- $\alpha(30 \%)$, IL-12p40 (42\%), and IL-12p35/p40 (27\%, $P<0.01)$, consistent with the hypothesis that ATRA participates in endogenous anti-inflammatory feedback loops in the central nervous system. Matsushita et $\mathrm{al}^{29}$ reported that the retinoic acid receptor agonist, Am80 (tamibarotene), currently in clinical use for the treatment of acute promyelocytic leukemia, was effective in treating intracerebral hemorrhage, which accompanies inflammatory reactions in the brain. Using an adult mouse model of intracerebral hemorrhage induced by intrastriatal injection of collagenase, daily oral administration of Am80 significantly inhibited the decrease in the number of striatal neurons 3 days after the insult. Prominent expression of RAR $\alpha$ was observed in activated microglia and macrophages. The number of activated microglia/macrophages was also lower in Am80-treated mice compared with controls, suggesting that the retinoic acid receptor is a promising target of neuroprotective therapy for intracerebral hemorrhage.

Many other studies using neuronal and glial cell cultures also point to the beneficial effects of retinoic acid, suggesting that future therapeutic approaches should focus on the activation of retinoic acid signaling. ${ }^{30}$ In fact, retinoic acid has become the standard treatment for acute promyelocytic leukemia and has improved the complete remission rate. ${ }^{31}$ However, in general, supplementary vitamin A using retinyl esters or synthetic retinoids has only temporary benefits in cancer treatment and these appear to be outweighed over time by toxic effects, notably the occasionally fatal "retinoic acid syndrome" characterized by respiratory distress, pulmonary infiltrates, fever, hypotension, weight gain, renal failure, and leg edema. ${ }^{32-34}$

By the early 1980s, the disappointing results of treatment with retinoids led to the hypothesis that the presumed deficiency of vitamin A in cancer was not due to reduced intake of preformed vitamin A but to reduced intake of plant sources of vitamin A, ie, carotenoids. Thus, it was suggested that supplementation with $\beta$-carotene, possibly combined with preformed vitamin A, could be a safe and effective approach to the treatment of cancer. ${ }^{35}$ Today, the search continues for less toxic retinoid compounds, and there are now over 4000 natural and synthetic molecules structurally or functionally related to vitamin A. ${ }^{34}$ Yet the surprising result of several subsequent long-term clinical trials of supplementary $\beta$-carotene 
and vitamin A for lung cancer prevention, involving thousands of men and women at high risk, was that these agents has no beneficial effect in preventing cancer and were instead associated with significant increases in lung cancer, cardiovascular disease, and total mortality, notably in smokers. ${ }^{36,37}$ EUROSCAN (European Study on Chemoprevention With Vitamin A and N-Acetylcysteine) similarly showed an increased risk of lung cancer among smokers who received $\beta$-carotene. ${ }^{38} \mathrm{~A}$ recent systematic review of studies on the safety and efficacy of vitamin A and retinoid derivatives for the treatment and prevention of lung cancer concluded that evidence was lacking to support such uses. ${ }^{39}$

\section{Could prolonged exposure to retinoids contribute to the pathogenesis of cancer?}

These findings remain unexplained on the current paradigm that cancer is associated with a deficiency of vitamin A. The alternative hypothesis suggested here is that alterations in retinoid metabolism associated with increased retinoid accumulation, expression, and toxicity induced by, eg, cigarette smoking, the use of hair dyes, irradiation, and exposure to certain chemicals and viruses, may be a common pathway for the development of many forms of cancer. In the case of gliomas, excessive and/or repeated exposure of the glial cells to retinoic acid due to the aforementioned risk factors, as well as traumatic brain injury, may result in alterations in the expression of retinoid receptor isotypes characterized by increased expression of RAR $\alpha$ and reduced expression of RAR $\beta$.

Vitamin A is an essential micronutrient that regulates many biological processes through modulation of retinoic acid receptor-responsive genes, acting as a systemic antioxidant and participating in the modulation of diverse redox mechanisms involved in physiological and pathological processes. However, increasing evidence from bench and clinical studies indicates that retinoids in pharmacological amounts are neurotoxins and can induce pro-oxidant actions that can lead to impaired brain and lung function ${ }^{40}$ and induce cell damage, proto-oncogene activity, proliferation, and neoplastic transformation. ${ }^{41}$ Thus, dietary retinoic acid supplementation stimulates intestinal tumor formation and growth of multiple intestinal neoplasia in (Min) $/+$ mice).${ }^{42}$ Vitamin A supplementation also increases the expression of c-Jun while decreasing the expression of p53 and p21WAF1/CIF1; the increase in c-Jun produced a significant increase in cyclin D1 expression, suggesting that vitamin A supplementation at pharmacological doses increases the risk of adverse effects, including the risk of cancer. ${ }^{43}$ The literature also suggests that vitamin A supplementation induces neurotoxicity and that synthetic retinoid treatment for acne decreases metabolic rates in the cerebral cortex and increases the risk of suicide and depression. ${ }^{18}$ Vitamin A supplementation increases the risk of all-cause mortality, even at low doses. ${ }^{44}$

The results of the unsuccessful beta-carotene and vitamin A cancer prevention trials are tentatively explained as follows: long-term beta-carotene supplementation coupled with habitual smoking and/or alcohol intake induces inflammatory changes in the liver, leading to fatty liver and hepatocyte injury associated with increased liver enzymes. Liver damage impairs the synthesis and secretion of vitamin A and thereby lowers total vitamin A concentrations in the blood, lung, and liver. ${ }^{45,46}$ However, contrary to the view that the mechanism of ethanol toxicity involves inhibition of the enzymatic conversion of retinol to retinoic acid, it is hypothesized that liver damage due to habitual smoking and alcohol intake causes stored retinoic acids and toxic retinyl esters (unbound to protein) to leak into the circulation from damaged hepatocytes, inducing inflammation and structural damage in lung, brain, and other tissues; a long-term effect of this process is induction of carcinogenesis and/or vascular disease.

In support of this model, polar retinol metabolites extracted from liver tissues of rats fed either an alcoholic or isocaloric control diet caused marked toxicity to hepatocytes in a concentration-dependent and time-dependent manner. Toxicity was due to apoptosis, as shown by increases in sub-G1 cellular events, rapid loss of mitochondrial membrane potential, and activation of caspase- 9 and caspase- $3 .{ }^{47}$ Blocking the enzyme cytochrome P450 (CYP)2E1, which inhibits the formation of retinoic acid metabolites, protects against the development of alcoholic liver disease in animal studies. ${ }^{48}$ Ethanol is known to increase retinoic acid production in cerebellar astrocytes and in the cerebellum. ${ }^{49}$ Ethanol also increases retinoic acid in the adult rat hippocampus, liver and testis; feeding dams a liquid diet containing $6.5 \%$ ethanol from embryonic day 13-19 significantly increases retinoic acid levels in the fetal hippocampus and cortex. It was suggested by the authors that supraphysiological concentrations of retinoic acid may contribute to ethanolassociated pathological conditions, including cognitive dysfunction and fetal alcohol syndrome. ${ }^{50}$ The adverse effects of alcohol on vitamin A metabolism is the subject of a recent review. ${ }^{51}$ However, as noted, studies suggest a null or negative association between alcohol consumption and malignant brain tumors. ${ }^{12}$ 


\section{Temporary benefits of therapeutic retinoids}

Two possible explanations are suggested for the temporary beneficial effects of retinoic acid analogs. First, the drugs could induce feedback inhibition to the endogenous synthesis of retinoic acid in the target tissues. For instance, Barua et $\mathrm{al}^{52}$ found that a single oral dose of retinoic acid $(0.167 \mathrm{mM})$ in corn oil given to six healthy human subjects was associated with a mean decline in serum retinol levels of approximately $20 \%$ within one hour which lasted for 24 hours. The concept of feedback inhibition of retinol (and retinoic acid synthesis) is consistent with the notion that increased endogenous expression of retinoid rather than deficiency is associated with the pathogenesis of cancer. Thus, retinoic acid had opposite effects on a human glioblastoma cell line (GL-15) depending on its concentration. At low doses $(0.01-1 \mu \mathrm{M})$, retinoic acid increased the proliferation of GL-15 cells via activation of a constitutively present signal transduction factor (STAT-3), whereas at higher concentrations $(5-10 \mu \mathrm{M})$, retinoic acid inhibited GL-15 proliferation, induced apoptosis, and failed to activate STAT- $3 .^{53}$

A second possibility is that the modest therapeutic success of synthetic retinoic acid analogs could be due to their induction of increased RAR $\beta$ expression, which is eventually repressed by other factors, possibly a corrective increase in the RAR $\alpha$ isotype of the retinoic acid receptors. Indeed, there is evidence that $\operatorname{RAR} \beta$ is required for the antiproliferative effect exerted by retinoids and that RAR $\beta$ is a potential tumor suppressor agent. ${ }^{54}$ This brings us to the concept that imbalances in the expression of retinoic acid receptor isotypes may contribute to oncogenesis.

\section{Evidence of $R A R \alpha$ upregulation in glioma}

Endogenous changes in retinoid metabolism associated with increased retinoid accumulation, expression, and toxicity may be a common pathway for the development of many forms of cancer. In the case of glioma, excessive exposure of the glial cells to retinoic acid due to, eg, cigarette smoking, use of hair dyes, irradiation, and exposure to certain chemicals and viruses, as well as traumatic brain injury, may result in alterations in the expression of retinoid receptor isoforms, characterized by increased expression of RAR $\alpha$ and reduced expression of RAR $\beta$.

Although little is known about the postulated increase in RAR $\alpha$, there is growing evidence for the existence of RAR $\beta$ underexpression in cancer (see below). Evidence of increased
RAR $\alpha$ expression in brain tumors is sparse but, in apparent contradiction to our thesis, Kleinschmidt-DeMasters et al ${ }^{55}$ found that RAR $\alpha$ was clearly altered in lung cancer tissue, and there was increased nuclear expression in metastatic melanomas and in lung carcinoma, but no upregulation (by nuclear staining) of RAR $\alpha$ in gliomas.

\section{RAR $\beta$ as a tumor inhibitor}

RAR $\beta$ is unique among the members of retinoic acid receptor isotype family because its gene expression is lost during the early development of numerous tumors. RAR $\beta$ also has a demonstrated unique role as a tumor suppressor protein and regulator of retinoid inhibition of cell proliferation in several types of cancer. RAR $\beta$-deficient mice also display abnormalities in the vitreous body in the eyes and impaired abilities in locomotion and motor coordination. RAR $\beta 2$, in particular, is suppressed at early stages of carcinogenesis, so agonists can be expected to be useful only in combination with agents that can reverse the silencing of $\operatorname{RAR} \beta 2 .{ }^{54}$ What causes RAR $\beta 2$ silencing? It is proposed that the silencing agent is RAR $\alpha$, due to excessive and prolonged exposure to retinoic acid. If this is the case, a RAR $\alpha$ antagonist in combination with a RAR $\beta$ agonist might be effective in the treatment of glioma and possibly other tumors.

\section{Proposed treatment of glioma}

A more targeted approach involving the different isotypes and isoforms of the retinoic acid receptor and retinoid $\mathrm{X}$ receptor appears to be needed for treating cancer. If the present hypothesis is correct, and RAR $\alpha$ is involved in tumor pathogenesis, then administration of retinoic acid analogs would be expected ultimately to worsen the disease. A more effective approach suggested by the hypothesis would be to combine an RAR $\alpha$ antagonist with an RAR $\beta$ agonist. However, no study to date has examined the impact of an RAR $\alpha$ antagonist as a potential treatment for cancer. As noted, treatment strategies to date involving retinoids have been based on the supposition that a retinoid deficiency contributes to the development of cancer. Hence, it would be thought inappropriate to use an RAR $\alpha$ antagonist as a potential treatment. Therefore, it remains an open question as to whether or not the combination of an RAR $\alpha$ antagonist and an RAR $\beta$ agonist would be more effective than an RAR $\beta$ agonist alone.

It is of special interest that the first RAR $\alpha$ antagonist (Ro41-5253) to be developed ${ }^{56}$ is a peroxisome proliferatoractivator receptor-gamma (PPAR $\gamma$ ) agonist, in that it can bind and activate PPAR $\gamma$, albeit weakly ${ }^{57}$ PPAR $\gamma$ is a master 
regulator of adipocyte differentiation and a target of the widely prescribed antidiabetic thiazolidinediones. Studies indicate that PPAR $\gamma$ ligands (such as ciglitazone) regulate differentiation and induce cell growth arrest and apoptosis in a variety of cancer types. ${ }^{58}$ These observations support the present hypothesis insofar as they suggest that expression of PPAR $\gamma$ is effectively equivalent to RAR $\alpha$ antagonism, ie, $\mathrm{RAR} \alpha$ antagonism is a natural consequence of PPAR $\gamma$ activation or expression. On the other hand, clinical trials to date indicate that PPAR $\gamma$ agonists are not useful as monotherapy for common cancers. ${ }^{59}$ PPARs bind to DNA as heterodimers with retinoid $\mathrm{X}$ receptors, and a synthetic retinoid $\mathrm{X}$ receptor agonist (6-OH-11-O-hydroxyphenantrene, IIF) has been found to have strong antitumor activity; in addition, combined use of the PPAR $\gamma$ ligand ciglitazone and the retinoid $\mathrm{X}$ receptor agonist IIF enhanced the effects of ciglitazone on the inhibition of glioblastoma and melanoma cell growth and tissue invasion. ${ }^{58}$

RAR $\alpha$ and $\operatorname{RAR} \beta$ are functionally interdependent in that, if RAR $\alpha$ is antagonized, endogenous beta signaling is not activated, an effect that could be overcome by providing exogenous RAR $\beta$ agonist. ${ }^{60}$ Hence, the proposed use of an RAR $\alpha$ antagonist in cancer treatment would require simultaneous supplementation with an RAR $\beta$ agonist.

The suggestion that RAR $\beta$ could stimulate regeneration of normal brain tissue is supported by the observations that retinoic acid stimulates neurite outgrowth in vitro of both embryonic central and peripheral nervous system via activation of RAR $\beta 2$; regions of the cerebellum and cerebral cortex also express RAR $\beta 2$; RAR $\beta$ agonist-induced endogenous RAR $\beta$ expression occurs in a dose-dependent manner and neurite outgrowth by RAR $\beta$ can occur via phosphoinositide 3-kinase signature; and RAR $\beta$ activity through phosphoinositide kinase signaling also induces axonal outgrowth of descending corticospinal fibers and promotes functional recovery in a model of spinal cord injury. ${ }^{61}$ It is not yet known if an RAR $\beta$ agonist can restore damaged glial cells and serve as a treatment for glioblastoma.

\section{Conclusion}

Recurrence of malignant glioma is common within 2 years, despite treatment, and most clinical trials have a poor outcome. ${ }^{62}$ No curative treatment for glioma exists, and no further improvement in outcomes from surgery, radiotherapy, or classic cytotoxic chemotherapy is considered likely. New treatments are needed that target the specific tumor and its biology. An ideal agent would specifically target tumor cells in the infiltrated brain by binding to a receptor effectively expressed on tumor cells; it would not be toxic to normal brain tissue and it would either cross the blood-brain barrier with ease or be delivered directly to the extracellular space of the tumor. ${ }^{63}$ It remains for future research to determine whether these specifications will be met by the proposed combination of an RAR $\alpha$ antagonist and an RAR $\beta$ agonist for the treatment of glioma.

\section{Acknowledgment}

Roy Duhe is thanked for his helpful comments on this paper.

\section{Dedication}

This paper is dedicated to the memory of my son, Richard Mawson, who was diagnosed with an anaplastic oligoastrocytoma in September 2006 and died on July 9, 2010, aged 28.

\section{Disclosure}

The author reports no conflicts of interest in this work.

\section{References}

1. Wen PY, Kesari S. Malignant gliomas in adults. $N$ Engl $J$ Med. 2008;359:492-507.

2. Tabatabai G, Hegi M, Stupp R, Weller M. Clinical implications of molecular neuropathology and biomarkers for malignant glioma. Curr Neurol Neurosci Rep. 2012;12:302-307.

3. Croteau D, Mikkelsen T. Adults with newly diagnosed high-grade gliomas. Curr Treat Options Oncol. 2001;2:507-515.

4. Westphal M, Lamszus K. The neurobiology of gliomas: from cell biology to the development of therapeutic approaches. Nat Rev Neurosci. 2011;12:495-508.

5. National Cancer Institute at the National Institutes of Health. General information about childhood brain stem glioma. Available at: http:// www.cancer.gov/cancertopics/pdq/treatment/child-brain-stem-glioma/ Patient/page1. Accessed July 4, 2012.

6. Ohgaki H. Epidemiology of brain tumors. Methods Mol Biol. 2009;472:323-342.

7. National Cancer Institute at the National Institutes of Health. Brain and central nervous system cancers. Available at: http://www.cancer.gov/ aboutnci/servingpeople/snapshots/brain.pdf. Accessed July 4, 2012.

8. National Cancer Institute at the National Institutes of Health. State cancer profiles. Available at: http://statecancerprofiles.cancer.gov/ cgi-bin/quickprofiles/profile.pl?28\&076. Accessed July 4, 2012.

9. Preston-Martin S, Pogoda JM, Schlehofer B, et al. An international case-control study of adult glioma and meningioma: the role of head trauma. Int J Epidemiol. 1998;27:579-586.

10. Lee M, Wrensch M, Miike R. Dietary and tobacco risk factors for adult onset glioma in the San Francisco Bay Area (California, USA). Cancer Causes Control. 1997;8:13-24.

11. Burch JD, Craib KJ, Choi BC, Miller AB, Rish HA, Howe GR. An exploratory case-control study of brain tumors in adults. J Natl Cancer Inst. 1987;78:601-609.

12. Wrensch M, Minn Y, Chew T, Bondy M, Berger SM. Epidemiology of primary brain tumors: current concepts and review of the literature. Neuro Oncol. 2002;4:278-299.

13. Schlehofer B, Blettner M, Preston-Martin S, et al. Role of medical history in brain tumour development: Results from the international adult brain tumour study. Int J Cancer. 1999;82:155-160. 
14. Farwell JR, Dohrmann GJ, Flannery JT. Medulloblastoma in childhood: An epidemiological study. J Neurosurg. 1984;61:657-664.

15. Geissler E, Staneczek W. SV40 and human brain tumors. Arch Geschwulstforschung. 1998;58:129-134.

16. Strickler HD, Rosenberg PS, Devesa SS, Hertel J, Fraumeni JF Jr, Goedert JJ. Contamination of poliovirus vaccines with simian virus 40 (1955-1963) and subsequent cancer rates. JAMA. 1988;279: 292-295.

17. Penniston KL, Tanumihardjo SA. The acute and chronic toxic effects of vitamin A. Am J Clin Nutr. 2006;83:191-201.

18. Lane M, Bailey S. Role of retinoid signaling in the adult brain. Prog Neurobiol. 2005;75:275-293.

19. Theodosiou M, Laudet V, Schubert M. From carrot to clinic: an overview of the retinoic acid signalling pathway. Cell Mol Life Sci. 2010;67:1423-1445.

20. Maden M. Retinoic acid in the development, regeneration and maintenance of the nervous system. Nat Rev Neurosci. 2007;8:755-765.

21. Wang C, Kane MA, Napoli JL. Multiple retinol and retinal dehydrogenases catalyze all-trans-retinoic acid biosynthesis in astrocytes. $J$ Biol Chem. 2011;286:6542-6553.

22. Smith MA, Parkinson DR, Cheson BD, Friedman MA. Retinoids in cancer therapy. J Clin Oncol. 1992;10:839-864.

23. Környei Z, Gócza E, Rühl R, et al. Astroglia-derived retinoic acid is a key factor in glia-induced neurogenesis. FASEB J. 2007;21:2496-2509.

24. Wolbach SB, Howe PR. Tissue changes following deprivation of fatsoluble A vitamin. J Exp Med. 1925;42:753-777.

25. Tang XH, Gudas LJ. Retinoids, retinoic acid receptors, and cancer. Annu Rev Pathol. 2011;6:345-364.

26. See SJ, Levin VA, Yung WK, Hess KR, Groves MD. 13-cis-retinoic acid in the treatment of recurrent glioblastoma multiforme. Neuro Oncol. 2004;6:253-258.

27. Lu J, Zhang F, Zhao D, et al. ATRA-inhibited proliferation in glioma cells is associated with subcellular redistribution of $\beta$-catenin via upregulation of Axin. J Neurooncol. 2008;87:271-277.

28. van Neerven $S$, Nemes A, Imholz P, et al. Inflammatory cytokine release of astrocytes in vitro is reduced by all-trans retinoic acid. J Neuroimmunol. 2010;229:169-179.

29. Matsushita H, Hijioka M, Hisatsune A, Isohama Y, Shudo K, Katsuki H. A retinoic acid receptor agonist Am80 rescues neurons, attenuates inflammatory reactions, and improves behavioral recovery after intracerebral hemorrhage in mice. J Cereb Blood Flow Metab. 2011;31:222-234

30. Mey J. New therapeutic target for CNS injury? The role of retinoic acid signaling after nerve lesions. J Neurobiol. 2006;66:757-779.

31. Wang ZY, Chen Z. Acute promyelocytic leukemia: from highly fatal to highly curable. Blood. 2008;111:2505-2515.

32. Frankel SR, Eardley A, Heller G, et al. All-trans retinoic acid for acute promyelocytic leukemia. Ann Intern Med. 1994;120:278-286.

33. Su YC, Dunn P, Shih LY, et al. Retinoic acid syndrome in patients following the treatment of acute promyelocytic leukemia with all-trans retinoic acid. Chang Gung Med J. 2009;32:535-542.

34. Bushue N, Wan YJY. Retinoid pathway and cancer therapeutics. $A d v$ Drug Deliv Rev. 2010;62:1285-1298.

35. Peto R, Doll R, Buckley JD, Sporn MB. Can dietary beta-carotene materially reduce human cancer rates? Nature. 1981;290:201-208.

36. Omenn GS, Goodman GE, Thornquist MD, et al. Effects of a combination of beta carotene and vitamin A on lung cancer and cardiovascular disease. $N$ Engl J Med. 1996;334:1150-1155.

37. Hennekens CH, Buring JE, Manson JE, et al. Lack of effect of long-term supplementation with beta carotene on the incidence of malignant neoplasms and cardiovascular disease. $N$ Engl J Med. 1996;334:1145-1149.

38. De Vries N, Van Zandwijk N, Pastorino U. The EUROSCAN study: a progress report. Am J Otolaryngol. 1993;14:62-66.

39. Fritz H, Kennedy D, Fergusson D, et al. Vitamin A and retinoid derivatives for lung cancer: a systematic review and meta-analysis. PLoS One. 2011;6(6):e21107.
40. Pasquali MA, Schnorr CE, Feistauer LB, Gelain DP, Moreira JC. Vitamin A supplementation to pregnant and breastfeeding female rats induces oxidative stress in the neonatal lung. Reprod Toxicol. 2010;30:452-456.

41. Zanotto-Filho A, Schröder F, Moreira JCF. Differential effects of retinol and retinoic acid on cell proliferation: a role for reactive species and redox-dependent mechanisms in retinol supplementation. Free Radical Res. 2008:42:778-788.

42. Mollersen L, Paulsen JE, Olstorn HB, Knutsen HK, Alexander J. Dietary retinoic acid supplementation stimulates intestinal tumour formation and growth in multiple intestinal neoplasia (Min)/+ mice. Carcinogenesis. 2004;25:149-153.

43. Borras E, Zaragoza R, Morante M, et al. In vivo studies of altered expression patterns of $\mathrm{p} 53$ and proliferative control genes in chronic vitamin A deficiency and hypervitaminosis. Eur J Biochem. 2003;270:1493-1501.

44. Bjelakovic G, Nikolova D, Gluud LL, Simonetti RG, Gluud C. Mortality in randomized trials of antioxidant supplements for primary and secondary prevention: systematic review and meta-analysis. JAMA. 2007;297:842-857.

45. Leo MA, Lieber CS. Alcohol, vitamin A, and beta-carotene: adverse interactions, including hepatotoxicity and carcinogenicity. Am J Clin Nutr. 1999;69:1071-1085.

46. Li T, Molteni A, Latkovich P, Castellani W, Baybutt RC. Vitamin A depletion induced by cigarette smoke is associated with the development of emphysema in rats. $J$ Nutr. 2003;133:2629-2634.

47. Dan Z, Popov Y, Patsenker E, et al. Hepatotoxicity of alcohol-induced polar retinol metabolites involves apoptosis via loss of mitochondrial membrane potential. FASEB J. 2005;19:845-847.

48. Gouillon Z, Lucas D, Li J, et al. Inhibition of ethanol-induced liver disease in the intragastric feeding rat model by chlormethiazole. Proc Soc Exp Biol Med. 2000;224:302-308.

49. McCaffery P, Koul O, Smith D, Napoli JL, Chen N, Ullman MD. Ethanol increases retinoic acid production in cerebellar astrocytes and in cerebellum. Brain Res Dev Brain Res. 2004;153: 233-241.

50. Kane MA, Folias AE, Wang C, Napoli JL. Ethanol elevates physiological all-trans-retinoic acid levels in select loci through altering retinoid metabolism in multiple loci: a potential mechanism of ethanol toxicity. FASEB J. 2010;24:823-832.

51. Clugston RD, Blaner WS. The adverse effects of alcohol on vitamin $A$ metabolism. Nutrients. 2012;4:356-371.

52. Barua AB, Duitsman PK, Kostic D, Barua M, Olson JA. Reduction of serum retinol levels following a single oral dose of all-trans retinoic acid in humans. Int J Vitam Nutr Res. 1997;67:423-426.

53. Paillaud E, Costa S, Fages C, et al. Retinoic acid increases proliferation rate of GL-15 glioma cells, involving activation of STAT-3 transcription factor. J Neurosci Res. 2002;67:670-679.

54. Alvarez S, Germain P, Alvarez R, Rodríguez-Barrios F, Gronemeyer H, de Lera AR. Structure, function and modulation of retinoic acid receptor beta, a tumor suppressor. Int J Biochem Cell Biol. 2007;39: 1406-1415.

55. Kleinschmidt-DeMasters BK, Orr EA, Savelieva E, Owens GC, Kruse CA. Paucity of retinoic acid receptor alpha (RAR alpha) nuclear immunostaining in gliomas and inability of retinoic acid to influence neural cell adhesion molecule (NCAM) expression. J Neurooncol. 1999;41:31-42.

56. Apfel C, Bauer F, Crettaz M, et al. A retinoic acid receptor alpha antagonist selectively counteracts retinoic acid effects. Proc Natl Acad Sci U S A. 1992;89:7129-7133.

57. Schupp M, Curtin JC, Kim RJ, Billin AN, Lazar MA. A widely used retinoic acid receptor antagonist induces peroxisome proliferatoractivated receptor- $\gamma$ activity. Mol Pharmacol. 2007;71:1251-1257.

58. Papi A, Rocchi P, Ferreri AM, Guerra F, Orlandi M. Enhanced effects of PPAR $\gamma$ ligands and RAR selective retinoids in combination to inhibit migration and invasiveness in cancer cells. Oncol Rep. 2009;21:1083-1089.

59. Krishnan A, Nair SA, Pillai MR. Biology of PPAR gamma in cancer: a critical review on existing lacunae. Curr Mol Med. 2007;6:532-540. 
60. Desai TJ, Chen F, Lü J, et al. Distinct roles for retinoic acid receptors alpha and beta in early lung morphogenesis. Dev Biol. 2006;291:12-24.

61. Agudo M, Yip P, Davies M, et al. A retinoic acid receptor beta agonist (CD2019) overcomes inhibition of axonal outgrowth via phosphoinositide 3-kinase signalling in the injured adult spinal cord. Neurobiol Dis. 2010;37:147-155.
62. Jaeckle KA, Hess KR, Yung WK, et al; North American Brain Tumor Consortium. Phase II evaluation of temozolomide and 13-cis-retinoic acid for the treatment of recurrent and progressive malignant glioma: a North American Brain Tumor Consortium study. J Clin Oncol. 2003;21:2305-2311.

63. Warnke PC. A 31-year-old woman with a transformed low grade glioma. JAMA. 2010;303:967-976.

\section{Publish your work in this journal}

Cancer Management and Research is an international, peer-reviewed open access journal focusing on cancer research and the optimal use of preventative and integrated treatment interventions to achieve improved outcomes, enhanced survival and quality of life for the cancer patient The journal welcomes original research, clinical \& epidemiological studies, reviews \& evaluations, guidelines, expert opinion \& commentary, case reports \& extended reports. The manuscript management system is completely online and includes a very quick and fair peerreview system, which is all easy to use. Visit http://www.dovepress.com/ testimonials.php to read real quotes from published authors.

Submit your manuscript here: http://www.dovepress.com/cancer-management-and-research-journal 